И мечение)

(C) Тахтарова Т.Г. ${ }^{*}$, Хисматуллина 3.Р. ${ }^{2}$, Панова Л.Д. ${ }^{2}$, Панова А.Н. ${ }^{2}$

\author{
1 Республиканская клиническая инфекционная больница \\ 450015, Россия, Республика Башкортостан, г. Уфра, ул. Запотоцкого, д. 37 \\ 2 Башкирский государственный медицинский университет \\ 450008, Россия, Республика Башкортостан, г. Усра, ул. Ленина, д. 3
}

Ихтиоз представляет собой заболевание кожи, которое является наследственным, имеет выраженную симптоматику в виде нарушения кожных покровов и наличия образований, напоминающих чешую рыбы. Можно выделить различные подходы к определению ихтиоза, основанные на современном изучении данного вопроса. Ихтиоз классифицируется по типу: врожденный и приобретенный. Врожденный ихтиоз имеет свою классификацию в зависимости от проявления изменений кожного покрова, течения заболевания, сопутствующих патологий. Врожденный ихтиоз подразделяется на обыкновенный (вульгарный аутосомно-доминантный, простой) ихтиоз, пластинчатый ихтиоз (сухая ихтиозифрормная эритродермия, «коллодиевый ребенок», ламеллярный ихтиоз), Х-сцепленный ихтиоз (ихтиоз, связанный с Х-хромосомой, чернеющий ихтиоз), врожденная буллезная ихтиозифрормная эритродермия (эритродермия Брока, ихтиозиформный эпидермолитический гиперкератоз), ихтиоз плода (ихтиоз внутриутробный, гиперкератоз универсальный, «плод Арлекин», кератоз врожденный), другой врожденный ихтиоз. Ихтиозиформные состояния (так называемый приобретенный ихтиоз) подразделяются на симптоматический, возрастной (старческий), дисковидный ихтиоз. Причинами приобретенного ихтиоза могут быть различные заболевания, прием препаратов, неправильный уход за кожей, несбалансированное питание. Каждая форма ихтиоза отличается типом наследования, распространенностью в популяции, клинической картиной, верифицируется с помощью гистологического исследования биоптатов кожи и электронно-микроскопического исследования кожи. Может сопровождаться сезонностью обострения клинической картины, ассоциацией с другими заболеваниями (аллергическими, заболеваниями желудочно-кишечного тракта, врожденными аномалиями развития). Специфического лечения ихтиоза не существует. В системной терапии применяют производные витамина группы A, для наружного лечения используют кератолитики, а также увлажняющие и смягчающие средства. Эфрфективно применение лечебных ванн, общего ультрафиолетового облучения.

Ключевые слова: ихтиоз, врожденный ихтиоз, приобретенный ихтиоз, изменение кожного покрова, шелушение, чешуи, гистопатология, клиническая картина.

Конфрликт интересов: авторы данной статьи подтвердили отсутствие конфрликта интересов, о котором необходимо сообщить.

Источник фринансирования: работа выполнена и опубликована за счет финансирования по месту работы авторов.

Для цитирования: Тахтарова Т.Г., Хисматуллина З.Р., Панова Л.Д., Панова А.Н. Ихтиоз (понятие, патогистология, клиническая картина, лечение). Вестник дерматологии и венерологии. 2021;97(3):06-13. doi: https://doi.org/10.25208/vdv1214 


\title{
Ichthyosis (concept, pathohistology, clinical picture, treatment)
}

\author{
(C) Tatyana G. Takhtarova ${ }^{1 *}$, Zarema R. Hismatullina², Lyudmila D. Panova², Anastasia N. Panova²
}

\author{
${ }^{1}$ Republican Clinical Infectious Diseases Hospital \\ Zapotockogo str., 37, 450015, Ufa, Republic of Bashkortostan, Russia \\ ${ }^{2}$ Bashkir State Medical University \\ Lenina str., 3, 450008, Ufa, Republic of Bashkortostan, Russia
}

Ichthyosis is a skin disease that is hereditary, has pronounced symptoms in the form of a violation of the skin, and the presence of formations resembling fish scales. We can distinguish different approaches to the definition of ichthyosis, based on the current study of this issue. Ichthyosis is classified by type: congenital and acquired. Congenital ichthyosis has its own classification, depending on the manifestation of changes in the skin, the course of the disease, and accompanying pathologies. Congenital ichthyosis is divided into ordinary (vulgar autosomal dominant, simple) ichthyosis, lamellar ichthyosis (dry ichthyosiform erythroderma, "collodion baby", lamellar ichthyosis), X-linked ichthyosis (ichthyosis associated with the X chromosome, blackening ichthyosis), congenital bullous ichthyosiform erythroderma (erythroderma Broca's disease, ichthyosiform epidermolytic hyperkeratosis), fetal ichthyosis (intrauterine ichthyosis, universal hyperkeratosis, "harlequin fruit", keratosis congenital), other congenital ichthyosis. Ichthyosiform conditions (so-called acquired ichthyosis) are divided into symptomatic, age-related (senile), discoid ichthyosis. The causes of acquired ichthyosis can be various diseases, medication, improper skin care, unbalanced nutrition. Each form of ichthyosis differs in the type of inheritance, prevalence in the population, clinical picture, verified by histological examination of skin biopsies and electron microscopic examination of the skin. It may be accompanied by seasonal exacerbation of the clinical picture, Association with other diseases (allergies, diseases of the gastrointestinal tract, congenital malformations). There is no specific treatment for ichthyosis. In systemic therapy, vitamin A derivatives are used, keratolytics are used for external treatment, as well as moisturizers and emollients. Effective use of therapeutic baths, General ultraviolet irradiation.

Keywords: ichthyosis, congenital ichthyosis, acquired ichthyosis, skin changes, peeling, scales, histopathology, clinical situation.

Conflict of interest: the authors of this article have confirmed that there is no conflict of interest to report.

Source of funding: the work was done and published through financing at the place of work of the authors.

For citation: Takhtarova TG, Hismatullina ZR, Panova LD, Panova AN. Ichthyosis (concept, pathohistology, clinical picture, treatment). Vestnik Dermatologii i Venerologii. 2021;97(3):06-13. doi: https://doi.org/10.25208/vdv1214 
Введение

Ихтиоз (в переводе с греческого - рыба, рыбья чешуя) представляет собой заболевание кожи, проявляющееся развитием кожных чешуек, которые напоминают рыбью чешую. Ихтиоз является описательным термином, обозначающим различные клинические формы генерализованного нарушения кератинизации. В основе данного заболевания лежат генетические нарушения, которые френотипически могут проявляться либо только в коже (несиндромный ихтиоз, изолированный), либо сочетаться с поражением других органов (синдромальный ихтиоз) [1, 2].

\section{Раздел 1}

Наследственные ихтиозы классифицируются как менделевские нарушения ороговения, которые определяются на основе клинико-генетических особенностей. Многочисленные гены, кодирующие соответствующие белки, участвуют в нормальной дифроеренцировке кератиноцитов, фрормирующих функциональный эпидермальный барьер. На сегодняшний день известно, что мутации более чем в 50 генах приводят к различным типам ихтиоза. Благодаря современным генетическим методам диагностики, а именно секвенированию нового поколения (NGS), примерно 80-90\% случаев могут быть исследованы таким образом в настоящее время. Значительный прогресс в понимании молекулярных механизмов ихтиозов был достигнут за последние 25 лет. NGS стала ключевой технологией генетического тестирования и применяется в рутинной диагностике наследственных заболеваний, поскольку затраты невелики, а результат быстр и эффрективен [3-5]. Клинические проявления заболевания типичны и характеризуются в основном тремя главными компонентами: фолликулярным гиперкератозом, шелушением, гиперлинеарным рисунком ладоней [6]. У большинства больных ихтиозом отмечается диффууное поражение кожи на боковых поверхностях туловища и разгибательных поверхностях конечностей в виде фолликулярных папул с роговой чешуйкой на поверхности, роговых чешуек различного размера и цвета - от белого до серовато-коричневого. Также наблюдаются трахионихии и онихорексис, ломкость и тусклость волос [7-9].

\section{Раздел 2}

В дерматологической практике в России используют международную статистическую классификацию болезней (МКБ-10), относящую ихтиозы к классу «Врожденные аномалии, деформации и хромосомные нарушения», рубрике «Другие врожденные аномалии», и включают: Q80.0 «Ихтиоз простой», Q80.1 «Ихтиоз, связанный с X-хромосомой», Q80.2 «Пластинчатый, ламинарный ихтиоз», Q80.3 «Врожденная буллезная ихтиозифрормная эритродермия», Q80.4 «Ихтиоз плода», Q80.8 «Другой врожденный ихтиоз» [10].

Ихтиозиформные состояния (так называемый приобретенный ихтиоз) имеют следующую классификацию: симтоматический; возрастной (старческий); дисковидный ихтиоз [11].

Обыкновенный ихтиоз представляет собой наиболее распространенный вид ихтиоза, который развивается и прогрессирует с двухмесячного возраста, иногда на более позднем этапе - в возрасте до 5 лет. Тип наследования: аутосомно-доминантный. Заболе- вание связано с мутацией в гене FLG, локализующемся на хромосоме 1q22. В результате нарушается синтез профилаггрина - предшественника филаггрина, последний, распадаясь в роговом слое эпидермиса на аминокислоты (транс-UCA и PCA), образует натуральный увлажняющий фрактор NMF, фрункция которого - удерживать воду и поддерживать требуемое значение $\mathrm{pH}$. Распространенными являются мутации R510X, 2282del4 и R2447X, которые были исследованы в работах С. С. Амелиной и Н. А. Живайкиной. В результате этих исследований выяснено, что наиболее частой мутацией является 2282del4, клиническая картина не зависит от вида мутации, у пациентов с компаунд-гетерозиготами 2282del4/R2447X и 2282del4/ R510X отмечалось проявление признаков ихтиоза с рождения $[12,13]$. При гистологическом исследовании кожи выявляют ретенционный гиперкератоз, гипогранулез или агранулез, образование кератотических пробок в устьях волосяных фолликулов. При электронно-микроскопическом исследовании отмечаются низкая диффференциация тонофибрилл, уменьшение и атипия зерен кератогиалина в зернистом слое, усиление рибосомальной активности в эпидермисе. Клинически обыкновенный ихтиоз проявляется шелушением пораженных участков (чаще на разгибательных поверхностях конечностей) и образованием мелких чешуек от белого до коричневого цвета. Отмечается фолликулярный гиперкератоз, повышенная складчатость ладоней и подошв. Волосы у пациентов редкие и истонченные, а ногтевые пластины ломкие и крошатся, может развиться онихолизис. Обыкновенный ихтиоз сопровождает своего носителя на протяжении всей жизни, состояние становится немного лучше летом, в зимний период наблюдается ухудшение. Часто обыкновенный ихтиоз сочетается с атопическими процессами, такими как атопический дерматит, бронхиальная астма [14].

Ихтиоз, связанный с Х-хромосомой, является $\mathrm{X}$-сцепленным рецессивным дерматозом, вызванным дефицитом фермента стероидной сульфатазы. Его распространенность составляет от 1:2000 до 1:6000 мужчин по всему миру без каких-либо значимых географических или расовых различий [6, 7]. Клинически характеризуется генерализованной сухостью и шелушением кожи, преимущественно поражая туловище, уши, шею, кожу волосистой части головы и конечности, обычно щадя кожу ладоней и подошв, а также лицо, подмышечные впадины, область гениталий. В переходном возрасте патологические изменения на коже волосистой части головы, лица и шеи ослабевают. Начало симптомов - при рождении или в течение первых месяцев жизни появляются чешуйки, которые более заметны на разгибательных участках конечностей. Чешуйки полигональной фрормы, толстые, плотно прикрепленные к коже, различаются по цвету, причем 70\% из них кажутся темно-коричневыми, а 30\% светло-серого цвета. Визуально кожные изменения схожи с таковыми при вульгарном ихтиозе, при этом фолликулярный кератоз и поражение кожи лица, ладоней и подошв отсутствуют, отмечается симптом «грязной кожи шеи». Х-сцепленный ихтиоз может возникать исключительно как кожное заболевание или может быть связано с другими аномалиями, такими как помутнение роговицы, крипторхизм, нарушение психики, умственная отсталость [15]. Патогенез 
Х-сцепленного ихтиоза связан со стероидной сульфатазой - это мембраносвязанный микросомальный фермент, который гидролизирует сульфаты ряда стероидов, преобразуя их в активную форму. Кодируется псевдоаутосомным геном на X-хромосоме, в ее коротком плече в сегменте Хр22.32. Примерно 90\% пациентов имеют полную делецию гена STS, а другие несут частичные делеции или точечные мутации в гене STS. Изменения гена STS, ведущие к недостаточности стероидной сульфатазы, приводят к избыточному накоплению холестеролсульфата в эпидермисе, повышенному сцеплению роговых чешуек и ретенционному гиперкератозу, также повышается проницаемость кожного барьера. Х-сцепленный ихтиоз может сочетаться с другими френотипическими аномалиями, такими как синдром Кальмана, точечная хондродисплазия, глазной альбинизм I типа и невысокий рост [16, 17].

Ихтиоз плода развивается на четвертом или пятом месяце беременности, наследуется аутосомно-рецессивно. Распространенность 1:300 000. В основе заболевания лежит мутация в гене АВСА12, расположенном на второй хромосоме. Данный ген регулирует диффреренцировку клеток рогового слоя и транспорт специфических протеаз, связанных с отшелушиванием кератиноцитов [18]. Гистологическая картина: пролиферативный гиперкератоз, акантоз, периваскулярные инфильтраты, гипертрофрия сосочков дермы, увеличение потовых и сальных желез. Электронно-микроскопически характеризуется многочисленными липидными включениями в кератиноцитах. Можно выявить данное заболевание пренатально (обнаружение дефицита стероидной сульфатазы в амниотической жидкости или в ткани хориона). Клиника проявляется с рождения, кожный покров в виде рогового панциря светлого цвета, который начинает темнеть в течение нескольких часов. Далее панцирь трескается, и на суставных поверхностях появляются глубокие трещины, бороздки. На голове толстый слой чешуек, волосы редкие, могут отсутствовать. Ротовое отверстие либо сильно растянуто, либо, наоборот, непроходимо даже зондом, в уголках рта образуются трещины, губы утолщены, а слизистая оболочка вывернута. Ушные раковины деформированы, в ноздрях и слуховых проходах роговые наслоения в виде пробок, выворот век, ресницы разряжены [19, 20].

Ихтиоз ламеллярный является редким врожденным заболеванием с частотой 1:200 000-1:300 000, поражая мужчин и женщин в равной степени. Наследование аутосомно-рецессивное и аутосомно-доминантное. При данном типе заболевания обнаружена мутация гена, кодирующего фермент транс-глутаминазу (TGM1) кератиноцитов (локус 14q11.2), что приводит к дефекту структуры рогового слоя и нарушению его десквамации. Патогистологическая картина: пролиферативный гиперкератоз, иногда паракератоз, умеренный акантоз, гипергранулез, очаговый спонгиоз, атрофия волосяных и сальных фолликул. Электронно-микроскопически выявляются нарушение метаболической активности эпителиоцитов, липидные включения в кератиноцитах, многочисленные пластинчатые гранулы в межклеточном пространстве. Клиническая картина ламеллярного ихтиоза проявляется с рождения: новорожденный находится в коллоидной пленке (коллоидный плод), затем к 6-7 месяцу начинается генерализованное шелушение. Постоян- ным клиническим признаком является ладонно-подошвенный гиперкератоз [21, 22].

Ихтиоз эпидермолитический примерно в половине случаев наследуется аутосомно-доминантно. Распространенность 1:300 000. Заболевание вызвано мутациями в генах KRT1 и KRT10. Пациенты с мутациями KRT1 имеют более тяжелые проявления по сравнению с пациентами с мутацией KRT10 [3]. Гистологическая картина: выраженный гиперкератоз, вакуольная и зернистая дистрофия гранулоцитов и клеток шиповатого слоя. Клиническая картина проявляется с рождения, кожа ребенка мацерированная, вскоре становится сухой с участками гиперкератоза от бурого до темно-серого цвета, в области крупных естественных складок, в которых появляются пузыри с серозным содержимым, присоединяется вторичная инфекция. Характерна сезонность, обострения весной и осенью [23-25].

Ихтиоз иглистый. Отношение к данной нозологии неоднозначно из-за неопределенности нозологического места. Предполагается аутосомно-доминантный тип наследования. Заболевание вызвано дефектом экспрессии кератина 1, связанного с мутациями KRT1. Патогистологическая картина: гиперкератоз, гранулез, акантоз, папилломатоз, дезорганизация зернистого слоя и вакуолизация клеток зернистого и шиповатого слоев за счет внутри- и межклеточного отека. Клиническая картина: с первых дней жизни появляются невыраженные симптомы иглистого ихтиоза, далее появляется шелушение и возникают бородавчатые роговые наслоения, выступающие на 5-10 мм [26-28].

В работах отечественных и зарубежных авторов приводятся многочисленные причины приобретенного ихтиоза: чрезмерный уход за кожей (встречается в основном у лиц зрелого возраста); злокачественные опухоли [29-32]; почечная недостаточность; аутоиммунные заболевания; иноекционные заболевания (как правило, ВИЧ инфекция и туберкулез); употребление определенных препаратов (гиполипидемические, психотропные, циметидин, клофазимин) [33]; недостаточно сбалансированное питание (недостаточность витамина А, кахексия) [34]; расстройства гормонального характера (гипотиреоз, гиперпаратиреоз, пангипопитуитаризм) [35, 36]; хронические воспалительные заболевания кишечника (неспецифический язвенный колит, болезнь Крона). Патогенез приобретенного ихтиоза до настоящего времени недостаточно изучен. Приобретенный ихтиоз, в отличие от наследственного ихтиоза, появляется в зрелом возрасте, чаще внезапно. Кожные проявления могут быть первым признаком опухолевого процесса или развиваться по мере прогрессирования заболевания. Клинически приобретенный ихтиоз напоминает вульгарный, гистологическая картина не отличается от таковой при наследственных формах ихтиоза. Постановке диагноза помогает тщательный сбор анамнеза, осмотр родственников пациента, выявление у больного сопутствующей патологии [37].

\section{Раздел 3}

Специфического лечения различных форм ихтиоза не существует. В основном используют производные витамина А, дозировка которых рассчитывается в зависимости от массы тела и степени выраженности клинических проявлений. Также в системной терапии 
назначают препараты цинка, витамины группы В и С. При легких фрормах ихтиоза можно использовать только наружную терапию и комплекс бальнеологических процедур, в более тяжелых случаях подключают системное лечение [38].

Наружное лечение вульгарного ихтиоза включает кератолитические средства: мочевина 2-5-10\%, салициловая 2-5\%, молочная $8 \%$, гликолевая кислоты 2 раза в сутки, а также увлажняющие смягчающие средства: крема и мази с ретинолом и эргокальциферолом 2-3 раза в сутки. При сочетании вульгарного ихтиоза и атопического дерматита не рекомендуется использование гликолевых кислот [10]. При выраженной сухости кожи и шелушении применяют ретинол 35006000 ME на килограмм массы тела перорально 1 раз в день 7-8 недель, постепенно уменьшая дозу вдвое. Благоприятное влияние на лечение вульгарного ихтиоза оказывает бальнеологическое лечение, а именно лечебные ванны, такие как сульфидные, хлориднонатриевые, кислородные, ванны с морской солью, крахмалом, содой, отваром ромашки, отрубями и общее ультрафиолетовое облучение [39].

В лечении Х-сцепленного ихтиоза применяется местная терапия и бальнеологическое лечение, как при простом ихтиозе. Системно применяется ретинол 6000-8000 ME на килограмм массы тела в течение 8 недель, при необходимости повторные курсы через 3-4 месяца $[40,41]$.

В терапии ламеллярного ихтиоза и эритродермии Брока используется ацитретин 0,3-0,5 мг на килограмм массы тела 1 раз в день перорально. В комплексном лечении пластинчатого ихтиоза отличный результат показывает фрототерапия [42, 43].

Новорожденные дети при ихтиозе плода нуждаются в интенсивной терапии в условиях инкубатора с первых дней жизни, что увеличивает эффективность лечения. Проводится коррекция водно-электролитного баланса, применяются системные антибиотики, глюкокортикостероиды (преднизолон 2-5 мг на килограмм массы тела) 1-1,5 месяца с постоянным снижением дозы до полной отмены. Применение кератолитических средств не рекомендуют [20].

При лечении ихтиоза должны быть достигнуты такие цели, как заживление трещин и эрозий, уменьшение шелушения, предупреждение и устранение присоединения инфекции. Для всех пациентов проводится индивидуальный подбор увлажняющих и смягчающих средств. Для профрилактики нужно отказаться от мытья кожи щелочным мылом, ограничить контакт с аллергизирующими веществами шерсти животных и бытовой химии [38].

\section{Раздел 4}

Нельзя не отметить важность терапевтического образования пациента и членов его семьи при ихтиозе. Дети и подростки, больные данным заболеванием, отмечают сильное чувство отчуждения среди сверстников, а также недопонимание по поводу своего заболевания. Помимо социальных трудностей отмечаются различные индивидуальные фризиологические отклонения - отсутствие эластичности кожи может огра- ничивать суставные движения, препятствовать росту пальцев, мешать мелкой моторике, ходьбе. Ни дети, ни их родители зачастую не понимают, как можно предотвратить эти двигательные и сенсорные осложнения. Цель терапевтического образования больных детей состоит в том, чтобы помочь им лучше понять свою болезнь, необходимость выполнения ежедневного ухода за кожей и других процедур для их выживания и комфорта [44, 45]. Кожные симптомы оказывают значительное влияние на качество жизни пациентов, но мало что известно о бремени (психологическом, социальном, экономическом, физическом) этого заболевания на семьи пациентов. В настоящее время существуют специальные опросники, позволяющие оценивать каждое из измерений (боль, повседневная жизнь, семейные и личные отношения, работа и психологическое воздействие), чтобы выразить нагрузку этого заболевания на пациента и членов его семьи $[46,47]$.

Ежедневный уход за больными ихтиозом требует немало времени и терпения, а также больших финансовых затрат. Ведение ихтиоза затруднено в семьях с низким уровнем дохода. Несвоевременное оказание поддерживающего лечения повышает риски обезвоживания, нарушения электролитного баланса, переохлаждения, присоединения инфекции и дальнейшего повреждения кожи и глаз. К счастью, в настоящее время существуют благотворительные фонды помощи больным ихтиозом [48].

\section{Заключение}

Ихтиоз представляет собой наследственное заболевание. Практически все виды ихтиоза проявляются сразу после рождения и прогрессируют со временем, а также сопровождаются различными другими необратимыми патологическими изменениями в организме человека. Мутации более чем в 50 генах приводят к развитию различных типов ихтиоза, но благодаря методике секвенирования нового поколения (NGS) в настоящее время может быть диагностировано около 80-90\% случаев. Клиническая картина со стороны кожных покровов проявляется в виде избыточного шелушения. Для того чтобы развился приобретенный ихтиоз, необходимо сочетание ряда фракторов (неправильный уход за кожей, различные заболевания, употребление лекарственных средств, недостаточно сбалансированное питание, расстройства гормонального характера). Для диагностики ихтиоза используются подробный анамнез, данные клинической картины, гистологического и электронно-микроскопического исследований. Специфического лечения ихтиоза не существует, в системной терапии применяют производные витамина группы $A$, для наружного лечения используют кератолитики, а также увлажняющие и смягчающие средства в комплексе с лечебными ваннами и фототерапией. В настоящее время огромная значимость придается обучению больных ихтиозом и их родственников навыкам ежедневного ухода за кожей и необходимым процедурам для комфортного выживания, а также психологической поддержке и социальной адаптациии. 


\section{Литература/References}

1. Платонова А.Н., Бакулев А.Л., Утц С.Р. Дерматовенерология. Атлас. М.: ГЭОТАР-Медиа; 2017. С. 136. [Platonova AN, Bakulev AL, Utc SR. Dermatovenerologija. Atlas. Moscow: GJeOTAR-Media; 2017. P. 136 (In Russ.)]

2. Дворянкова Е.В., Мельниченко 0.0., Красникова В.Н., Корсунская И.М. Ихтиоз. Что важно знать специалисту. РМЖ Медицинское обозрение. 2019;12:25-30. [Dvorjankova EV, Mel'nichenko 00, Krasnikova VN, Korsunskaja IM. Ihtioz. Chto vazhno znat' specialist. RMZh Medicinskoe obozrenie. 2019;12:25-30 (In Russ.)]

3. Fischer J, Bourrat E. Genetics of Inherited Ichthyoses and Related Diseases. Acta Derm Venereol. 2020;100(7):adv00096.

doi: 10.2340/00015555-3432

4. Кошкин С.В., Чермных Т.В., Евсеева А.Л., Рябова В.В., Рябов А.Н. Ламеллярный врожденный ихтиоз. Вестник дерматологии и венерологии. 2016:5:44-50. [Koshkin SV, Chermnyh TV, Evseeva AL, Ryabova VV, Ryabov AN. Lamelljarnyj vrozhdennyj intioz. Vestnik dermatologii i venerologii. 2016;5:44-50 (In Russ.)]

5. Marukian NV, Choate KA. Recent advances in understanding ichthyosis pathogenesis. F1000Research. 2016;5:1497.

doi: 10.12688/f1000research.8584.1

6. Скрипкин Ю.К. Дерматовенерология. Национальное руководство. Под ред. Ю.К. Скрипкина, Ю.С. Бутова, О.Л. Иванова. М.: ГЭОТАР-Медиа; 2011. С. 1052. [Skripkin JuK. Dermatovenerologija. Nacional'noe rukovodstvo. JuK Skripkin, JuS Butov, OL Ivanova, editors. Moscow: GJeOTAR-Media; 2011. P. 1052 (In Russ.)]

7. Schmuth M, Martinz V, Janecke AR, Fauth C, Schossig A, Zschocke J, et al. Inherited ichthyoses/generalized Mendelian disorders of cornification. Eur J Hum Genet. 2013;21(2):123-133.

doi: 10.1038/ejhg.2012.121

8. Кубанова А.А. Дерматовенерология. Под ред. А.А. Кубановой. М.: ДЭКС ПРЕСС; 2010. С. 428. [Kubanova АA. Dermatovenerologija. AA Kubanov, editor. Moscow: DJeKS PRESS; 2010. P. 428 (In Russ.)]

9. Oji V, Tadini G, Akiyama M, Blanchet Bardon C, Bodemer C, Bourrat $E$, et al. Revised nomenclature and classification of inherited ichthyoses: results of the First Ichthyosis Consensus Conference in Sorèze 2009. J Am Acad Dermatol. 2010;63(4):607-641.

doi: 10.1016/j.jaad.2009.11.020

10. Федеральные клинические рекомендации. Дерматовенерология 2015: Болезни кожи. Инсекции, передаваемые половым путем. 5-е изд., перераб. и доп. М.: Деловой экспресс; 2016. С. 768. [Federal'nye klinicheskie rekomendacii. Dermatovenerologija 2015: Bolezni kozhi. Infekcii, peredavaemye polovym putem. 5-e izd., pererab. i dop. Moscow: Delovoj jekspress; 2016. P. 768 (In Russ.)]

11. Гараева 3.Ш. Основные концепции патогенеза и современного течения ихтиозов. Практическая медицина. 2013;73(1-4):17-19. [Garaeva ZSh. Osnovnye koncepcii patogeneza i sovremennogo techenija intiozov. Prakticheskaja medicina. 2013;73;1-4:17-19 (In Russ.)]

12. Живайкина Н.А., Малютина Е.В., Машкевич Д.А., Васильева М.А., Максимова Ю.В. Вариабельность мутаций гена филаггрина у больных с вульгарным ихтиозом. Медицинская генетика. 2020;19(8):105-106. [Zhivaikina NA, Malyutina EV, Mashkevich DA, Vasil'eva MA, Maksimova JuV. Mutation variability in the filaggrin gene in patients with ichthyosis vulgaris. Medical genetics. 2020;19(8):105-106 (In Russ.)] doi: 10.25557/2073-7998.2020.08.105-106

13. Амелина С.С., Дегтерева Е.В., Петрова Н.В. Марахонов А.В., Темников В.Е., Петрина Н.Е., и др. Распространенность вульгарного ихтиоза и частота мутаций R501X И 2282DEL4 в гене FLG в Ростовской области. Вестник РГМУ.2018;1:51-55. [Amelina SS, Degtereva EV, Petrova NV, Marahonov AV, Temnikov VE, Petrina NE, et. al. Prevalence of ichthyosis vulgaris and frequency of FLG R501X and 2282DEL4 mutations in the population of the Rostov region. Vestnik RGMU. 2018;1:51-55 (In Russ.)] doi: 10.24075/vrgmu.2018.009

14. Каплунов К.О. Случай врожденного вульгарного ихтиоза у ребенка на фоне первичного иммунодефицита. Волгоградский научно-медицинский журнал. 2017;54(2):45-47. [Kaplunov KO. Sluchaj vrozhdennogo vul'garnogo intioza u rebenka na fone pervichnogo immunodeficita. Volgogradskij nauchno-medicinskij zhurnal. 2017;54(2):4547 (In Russ.)]

15. Malik A, Amer AB, Salama M, Haddad B, Alrifai MT, Balwi MA, et al. X-linked ichthyosis associated with psychosis and behavioral abnormalities: a case report. J Med Case Rep. 2017;11(1):267.

doi: 10.1186/s13256-017-1420-2

16. Elias PM, Williams ML, Choi EH, Feingold KR. Role of cholesterol sulfate in epidermal structure and function: lessons from X-linked ichthyosis. Biochim Biophys Acta. 2014;1841(3):353-361.

doi: 10.1016/j.bbalip.2013.11.009

17. Ben Khelifa H, Soyah N, Ben-Abdallah-Bouhjar I, Gritly R, Sanlaville D, Elghezal $H$, et al. Xp22.3 interstitial deletion: a recognizable chromosomal abnormality encompassing VCX3A and STS genes in a patient with X-linked ichthyosis and mental retardation. Gene. 2013;527(2):578583. doi: 10.1016/j.gene.2013.06.018

18. Беликов А.Н., Альбанова В.И., Комлева Л.Ф., Гольченко В.А. Ихтиоз Арлекина (плод Арлекина): описание случая. Вестник дерматологии и венерологии.2012;88(3):80-85. [Belikov AN, Al'banova VI, Komleva LF, Gol'chenko VA. Ihtioz Arlekina (plod Arlekina): opisanie sluchaja. Vestnik dermatologii i venerologii. 2012;88(3):80-85. (In Russ.)] doi: $10.25208 / v d v 690$

19. Ходжаева Г.Т., Таджиддинов Э.Я., Юсупбаев Р.Б. Пренатальная диагностика редких врожденных пороков и синдромов. LVI. Врожденный ихтиоз. Пренатальная диагностика. 2012;11(4):324-328. [Hodzhaeva GT, Tadzhiddinov JeJa, Jusupbaev RB. Prenatal'naja diagnostika redkih vrozhdennyh porokov i sindromov. LVI. Vrozhdennyj ihtioz. Prenatal'naja diagnostika. 2012;11(4):324-328 (In Russ.)]

20. Sheth JJ, Bhavsar R, Patel D, Joshi A, Sheth FJ. Harlequin ichthyosis due to novel splice site mutation in the ABCA12 gene: postnatal to prenatal diagnosis. Int J Dermatol. 2018;57(4):428-433.

doi: $10.1111 /$ ijd.13923

21. Куклин И.А., Бочкарев Ю.М., Кеникссрест Ю.В., Артамонова М.А. Редкий случай лямеллярного ихтиоза. Вестник дерматологии и венерологии. 2011;87(2):49-53. [Kuklin IA, Bochkarev JuM, Keniksfest JuV, Artamonova MA. A rare case of lamellar ichthyosis. Vestnik dermatologii i venerologii. 2011;87(2):49-53 (In Russ.)]

doi: $10.25208 / v d v 995$

22. Hashimoto K, Gee S, Tanaka K. Lamellar Ichthyosis: response to etretinate with Transglutaminase 1 Recoveiy. Am. J. Dermatopath. 2000;22(3):277-280. doi: 10.1097/00000372-200006000-00014

23. Провизион А.Н., Мироненко Т.В., Провизион Л.Н. Семейный случай развития врожденной ихтиозиформной эритродермии Брока в нескольких поколениях. Украинский журнал дерматологии, венерологии, косметологии. 2014;1(52):88-92. [Provizion AN, Mironenko TV, Provizion LN. Semejnyj sluchaj razvitija vrozhdennoj intioziformnoj jeritrodermii Broka $v$ neskol'kih pokolenijah. Ukrainskij zhurnal dermatologii, venerologii, kosmetologii. 2014;1(52):88-92 (In Russ.)]

24. Дегтярев О.В., Меснянкина О.А., Янчевская Е.Ю., Шашкова А.А. Клиническое наблюдение эритродермии ихтиозиформной Брока. Российский журнал кожных и венерических болезней. 2015;18(2):4244. [Degtjarev OV, Mesnjankina OA, Janchevskaja EJu, Shashkova AA. 
Klinicheskoe nabljudenie jeritrodermii intioziformnoj Broka. Rossijskij zhurnal kozhnyh i venericheskih boleznej. 2015;18(2):42-44 (In Russ.)] doi: 10.17816/dv36970

25. Smith FJD, Kreuser-Genis IM, Jury CS, Wilson NJ, TerronKwiatowski A, Zamiri M. Novel and recurrent mutations in keratin 1 cause epidermolytic ichthyosis and palmoplantar keratoderma. Clin Exp Dermatol. 2019;44(5):528-534. doi: 10.1111/ced.13800

26. Кондратьева Ю.С., Сасонов Н.Е., Клеймуш В.А., Шипилов А.А. Семейный случай иглистого ихтиоза. Вестник дерматологии и венерологии. 2011;87(4):73-79. [Kondrat'eva JuS, Safonov NE, Klejmush VA, Shipilov AA. Family case of hystriciasis. Vestnik dermatologii i venerologii. 2011;87(4):73-79 (In Russ.)] doi: 10.25208/vdv1047

27. Елькин В.Д., Седова Т.Г., Плотникова Е.В., Кузнецов И.Д., Новоселова М.Ю. Иглистый ихтиоз или веррукозный эпидермальный невус (ретроспективный анализ 20-летнего наблюдения). Альманах клинической медицины. 2017;45(1):62-67. [El'kin VD, Sedova TG, Plotnikova EV, Kuznecov ID, Novoselova MJu. Ichthyosis hystrix disease or verrucous epidermal nevus (a retrospective analysis of 20-year observation). Almanac of Clinical Medicine. 2017;45(1):62-67 (In Russ.)] doi: 10.18786/2072-0505-2017-45-1-62-67

28. Гребенюк В.Н., Гришко Т.Н., Бассе Ф.Б., Текучева Л.В., Катунина О.Р. Иглистый ихтиоз: вопросы клиники, диагностики и лечения. Вестник дерматологии и венерологии. 2011;87(1):77-80. [Grebenjuk VN, Grishko TN, Basse FB Tekucheva LV, Katunina OR. Ichthyosis hystrix: clinical signs, diagnostics, and treatment. Vestnik dermatologii i venerologii. 2011;87(1):77-80 (In Russ.)] doi: 10.25208/vdv965

29. Корнеева Л.С., Мельниченко Н.Е. ГБОУ ВПО Амурская ГМА Минздрава России. Кафедра кожных и венерических болезней. Учебное пособие «Генодерматозы»; 2014. C. 142. [Korneeva LS, Mel'nichenko NE. GBOU VPO Amurskaja GMA Minzdrava Rossii. Kafedra kozhnyh i venericheskih boleznej. Uchebnoe posobie «Genodermatozy»; 2014. P. 142 (In Russ.)]

30. Tokuriki A, Kiyohara T, Ido T, Kumakiri M. A Case of lymphomatoid papulosis with extensive limb disease followed by extracutaneous involvement and acquired ichthyosis. Acta Derm Venereol. 2012;92(3):278-279. doi: 10.2340/00015555-1314

31. Tanita K, Fujimura T, Sato Y, Hidaka T, Furudate S, Kambayashi Y, et al. Successful treatment of primary cutaneous peripheral T-Cell lymphoma presenting acquired ichthyosis with oral bexarotene monotherapy. Case Rep Oncol. 2017:10(1):328-332. doi: 10.1159/000468981

32. Saldaña M, Montes de Oca G, Tirado-Sánchez A, Mercadillo P, Arellano-Mendoza Ml. Acquired ichthyosis associated with gastric adenocarcinoma. Int J Dermatol. 2018;57(6):713-714. doi: 10.1111/ijd.13988

33. Ko KD, Kim KK, Baek JO, Suh HS, Hwang IC. A Possible case of statin-induced ichthyosis in an elderly woman. Korean J Fam Med. 2018:39(1):51-53. doi: 10.4082/kjfm.2018.39.1.51.

34. Samuel B. Holzman and Samuel C. Durso. Nutritional Deficiency and Acquired Ichthyosis. J Gen Intern Med. 2017;32(10):1161-1162.

doi: 10.1007/s11606-017-4070-6

35. Peng T, Hu Z, Gao Z, Cai D, Yang X. Acquired ichthyosis and secondary hyperparathyroidism with systemic lupus erythematosus. Lupus. 2015;24(2):218-221. doi: 10.1177/0961203314554250

36. Brazzelli V, Larizza D, Muzio F, Fornara L, Calcaterra V, Vassallo C. Acquired ichthyosis in a child with autoimmune thyroiditis. Pediatr Dermatol. 2010;27(4):413-414. doi: 10.1111/j.1525-1470.2010.01172.x
37. Dermatology, third edition, 2-volume set. Jean L Bolognia MD, Joseph L Jorizzo MD, Julie V Schaffer, Editorial Saunders, Reino Unido, editors. ISBN-13:9780723435716, Elsevier, 2012. P. 2776

38. Dmitrenko S.V. Sequential therapy of ichthyosis: prospects for improvement. Ukrainian Journal of Dermatology, Venereology, Cosmetology. 2015;3(58):33-36.

39. Хамаганова И.В., Ломакина Е.А., Кашеваров Д.Ф. Федорова Ю.С. Лечебные средства увлажняющего действия в комплексной терапии вульгарного ихтиоза у детей. Дерматология. Приложение к журналу Consilium Medicum. 2013;4:17-20. [Hamaganova IV, Lomakina EA, Kashevarov DF, Fedorova JuS. Lechebnye sredstva uvlazhnjajushhego dejstvija v kompleksnoj terapii vul'garnogo intioza u detej. Dermatologija. Prilozhenie k zhurnalu Consilium Medicum. 2013;4:17-20 (In Russ.)]

40. Грэхем-Браун Р, Бурк Д, Канлиффф Т. Практическая дерматология. Р. Грэхем-Браун, Д. Бурк, Т. Канлифф; пер. с англ. Под ред. H.М. Шаровой. М.: МедПресс-информ; 2011. С. 360. [Grekhem-Braun R, Burk D, Kanliff T. Prakticheskaja dermatologija. R Grjehem-Braun, D Burk, T Kanliff; editors. Moscow: MedPress-inform; 2011. P. 360 (In Russ.)]

41. Дмитренко С.В., Вернигородский С.В. Морфологическая оценка эффеективности лечения ихтиоза с применением ретиноидов. Наука молодых. 2015;2:12-32. [Dmitrenko SV, Vernigorodskij SV. Morphological evaluation of the effectiveness treatment of ichthyosis with the use retinoids. Eruditio Juvenium. 2015;2:12-32 (In Russ.)]

42. Ефанова Е.Н., Улитина И.В., Иванникова Е.Н., Русак Ю.Э., Лакомова И.Н. Врожденный ихтиоз у новорожденного по типу «коллоидный плод». Российский журнал кожных и венерических болезней. 2015;18(6):26-28. [Efanova EN, Ulitina IV, Ivannikova EN, Rusak JuJe, Lakomova IN. Colloid fetus type congenital ichthyosis in a newborn. Russian Journal of Skin and Venereal Diseases. 2015;18(6):26-28 (In Russ.)]

43. Крапивина А.И., Колесникова Е.А., Тулинцев В.А. Фотохимиотерапия как один из эффеективных методов лечения ламеллярного ихти0за. Вестник научных конференций. 2018;40(12)107-108. [Krapivina Al, Kolesnikova EA, Tulincev VA. Fotohimioterapija kak odin iz jeffektivnyh metodov lechenija lamelljarnogo ihtioza. Vestnik nauchnyh konferencij. 2018;40(12):107-108 (In Russ.)] doi: 10.1186/1750-1172-8-113

44. Dufresne H, Hadj-Rabia S, Taïeb C, Bodemer C. Importance of therapeutic patient education in ichthyosis: results of a prospective single reference center study. Orphanet J Rare Dis. 2013;8:113.

doi: 10.1186/1750-1172-8-113

45. Mazereeuw-Hautier J, Hernández-Martín A, O'Toole EA, Bygum A, Amaro C, Aldwin M, et al. Management of congenital ichthyoses: European guidelines of care, part two. Br J Dermatol. 2019;180(3):484-495.

doi: 10.1111/bjd.16882

46. Белякова А.В., Васильева В.П., Новикова Л.А., Бахметьева Т.М. Качество жизни у больных с ихтиозом. Молодежный инновационный вестник. 2018;7(S1):138-139. [Beljakova AV, Vasil'eva VP, Novikova LA, Bahmet'eva TM. Kachestvo zhizni u bol'nyh s intiozom. Molodezhnyj innovacionnyj vestnik. 2018;7(S1):138-139 (In Russ.)]

47. Dufresne H, Hadj-Rabia S, Méni C, Sibaud V, Bodemer C, Taïeb C. Family burden in inherited ichthyosis: creation of a specific questionnaire. Orphanet J Rare Dis. 2013;8:28. doi: 10.1186/1750-1172-8-28

48. Saso A, Dowsing B, Forrest $K$, Glover M. Recognition and management of congenital ichthyosis in a low-income setting. BMJ Case Rep. 2019;12(8):e228313. doi: 10.1136/bcr-2018-228313 
Участие авторов: литературный обзор, сбор и обработка материала, редактирование - Т.Г. Тахтарова; литературный обзор, сбор и обработка материала, редактирование, оформление - 3.Р. Хисматуллина; сбор и обработка материала, редактирование - Л.Д. Панова; сбор и обработка материала, проведение инструментальных методов исследования, редактирование - А.Н. Панова.

Authors' participation: literary review, collection and statistical processing of the material, editing — Tatyana G. Takhtarova; literary review, collection and statistical processing of the material, editing, design — Zarema R. Hismatullina; collection and processing of the material, editing — Lyudmila D. Panova; collection and processing of the material, conducting instrumental research methods, editing — Anastasia N. Panova.

\section{Информация об авторах}

*Татьяна Геннадьевна Тахтарова — врач-инфекционист; адрес: Россия, Республика Башкортостан, 450074, г. Уфра, ул. Муксинова, д. 2/3, KB. 345; ORCID iD: https://orcid.org/0000-0001-8166296X; e-mail: tatitati030690@gmail.com

Зарема Римовна Хисматуллина - д.м.н., професcop; ORCID iD: https://orcid.org/0000-0001-8674-2803; eLibrary SPIN: 6602-4060; e-mail: hzr07@mail.ru

Людмила Дмитриевна Панова - д.м.н., просреccop; ORCID iD: https://orcid.org/0000-0001-7570-7420; eLibrary SPIN: 2228-6041; e-mail: zpokolenie2015@gmail.com

Анастасия Николаевна Панова - д.м.H.; ORCID iD: https://orcid.org/0000-0002-8685-9531; e-mail: zpokolenie2015@gmail.com

\section{Information about the authors}

*Tatyana G. Takhtarova - an infectious disease specialist; address: 2/3 Muksinova street, apt. 345, 450074, Ufa, Russia, Republic of Bashkortostan; ORCID iD: https://orcid.org/0000-0001-8166296X; e-mail: tatitati030690@gmail.com

Zarema R. Khismatullina - MD, Dr. Sci. (Med.), Professor; ORCID iD: https://orcid.org/0000-0001-8674-2803; eLibrary SPIN: 6602-4060; e-mail: hzr07@mail.ru

Lyudmila D. Panova - MD, Dr. Sci. (Med.), Professor; ORCID iD: https://orcid.org/0000-0001-7570-7420; eLibrary SPIN: 2228-6041: e-mail: zpokolenie2015@gmail.com

Anastasia N. Panova - MD, Dr. Sci. (Med.); ORCID iD: https://orcid.org/0000-0002-8685-9531; e-mail: zpokolenie2015@gmail.com

Статья поступила в редакцию: 15.02.2021

Принята к публикации: 12.04 .2021

Дата публикации: 15.06.2021
Submitted: 15.02 .2021

Accepted: 12.04 .2021

Published: 15.06.2021 